\title{
Professores da rede municipal de ensino e o conhecimento sobre o papel da escola na formação dos hábitos alimentares dos escolares
}

\section{Teachers of the municipal network education and knowledge about the school role in the formation of the eating habits of schoolchildren}

Aline dos Santos Rocha ${ }^{1}$. Vanessa Barbosa Facina ${ }^{2}$

\begin{abstract}
Resumo: O presente estudo verificou o conhecimento dos professores do Ensino Fundamental I acerca do papel da escola na formação dos hábitos alimentares dos escolares. Estudo longitudinal, quali-quantitativo realizado em escolas públicas municipais na cidade de Amargosa, BA, que estiveram imersas em um Programa de Educação para o Trabalho para a Saúde (PET/Saúde) por um período de três meses. Utilizou-se um questionário estruturado abordando questões sobre nutrição e saúde. Verificou-se os acertos e erros obtidos antes e após a intervenção do programa. Participaram do estudo 14 professoras, com mediana de idade de 41 anos, sendo a maioria pedagoga. Verificou-se diferença significante na questão referente à importância da escola na formação de hábitos alimentares dos escolares $(p=0,0425)$. Concluiu-se que os professores reconheceram o papel da escola na formação dos hábitos alimentares dos escolares e reconheceram-se como agentes fundamentais na promoção da alimentação saudável e da qualidade de vida no ambiente escolar.
\end{abstract}

Palavras-chave: Hábito alimentar. Ensino fundamental. Promoção da saúde. Nutrição. Alimentação.

\begin{abstract}
This study verified the knowledge of elementary school teachers about the school's role in shaping the students' eating habits. The paper describes a longitudinal study, qualitative and quantitative, conducted in public schools in the city of Amargosa, BA, which were immersed in an Education Program of Work for Health (PET/Health) for a period of three months. We used a structured questionnaire addressing issues of nutrition and health. It revealed the successes and mistakes made before and after the program intervention. The sample was composed of 14 teachers, with a median age of 41 years, most of them, pedagogues. There was statistical difference in the question of the importance of school in forming eating habits of children $(p=0.0425)$. It was concluded that teachers recognized the school's role in shaping the students' eating habits and were recognized themselves as key players in promoting healthy eating and quality of life at school.
\end{abstract}

Keywords: Food habit. Elementary school. Health promotion. Nutrition. Feeding.

\footnotetext{
${ }^{1}$ Universidade Federal da Bahia (UFBA), Escola de Nutrição, Salvador, BA, Brasil. E-mail: <linny_rochaa@ hotmail.com>.

${ }^{2}$ Universidade Federal do Recôncavo da Bahia (UFRB), Centro de Ciências da Saúde, Santo Antônio de Jesus, BA, Brasil.
} 


\section{Introdução}

Pesquisas realizadas nos últimos anos demonstram o aumento na prevalência de sobrepeso e obesidade no Brasil, sendo tal elevação verificada em populações de todas as classes econômicas e faixas etárias, inclusive crianças e adolescentes (ANZOLIN et al., 2010). A Pesquisa de Orçamentos Familiares (POF) de 2008-2009 revelou que uma em cada três crianças, de 5-9 anos de idade apresentava sobrepeso e 14,3\% obesidade, e entre os adolescentes, 10-19 anos de idade, 20,5\% apresentaram sobrepeso e 4,9\% obesidade (IBGE, 2010). Entre crianças e adolescentes, o excesso de peso está relacionado às mudanças estruturais nos hábitos alimentares, com maior ingestão de gorduras e açúcares e menor consumo de alimentos ricos em fibras; e ao lazer inativo com destaque para aumento do tempo de tela, relacionado às atividades como televisão, computador e vídeo game (ESCOBAR; VALENTE, 2007).

O sobrepeso/obesidade iniciados na infância e na adolescência podem permanecer na fase adulta e levar ao desenvolvimento de doenças crônicas não transmissíveis (DCNT) (MOTTER et al., 2015). Nesse sentido, programas de educação em saúde vêm sendo criados, em diversos países, como forma de prevenir DCNT, apontadas como a principal causa de morte na idade adulta (DAVANÇO; TADDEI; GAGLIANONE, 2004).

A Organização Mundial da Saúde (OMS), visando a promoção da saúde e a prevenção de doenças, lançou a iniciativa "Estratégia Global para Alimentação, Atividade Física e Saúde", aprovada em 2004 por 191 países, destacando-se entre as ações preconizadas aquelas visando à promoção de práticas alimentares saudáveis no âmbito escolar (WHO, 2004).

No Brasil, as diretrizes para a Promoção da Alimentação Saudável nas Escolas (BRASIL, 2006), o Programa Nacional de Alimentação Escolar (PNAE) (BRASIL, 2009) e a Política Nacional de Alimentação e Nutrição (PNAN) (BRASIL, 2012) compreendem algumas políticas públicas que preveem, entre outras ações, a incorporação do tema alimentação saudável no Projeto Político Pedagógico das escolas, contemplando o desenvolvimento contínuo de programas de promoção de hábitos alimentares saudáveis.

Nesse sentido, a escola deve assumir a responsabilidade pela educação em saúde devido a sua função social e a sua potencialidade para o desenvolvimento de um trabalho sistematizado e contínuo (SOBRAL; SANTOS, 2010). De acordo com os Parâmetros Curriculares Nacionais (BRASIL, 1997), dentro do capítulo relacionado ao tema transversal saúde, sugere-se que toda escola deva incorporar os princípios de promoção da saúde indicados pela OMS, com o objetivo de fomentar a saúde e o aprendizado em todos os momentos. Nesse processo de promoção da saúde na escola, profissionais de saúde, de educação, pais, alunos e demais membros da comunidade devem estar integrados no esforço de transformar a escola em um ambiente saudável.

Influenciada por fatores fisiológicos, psicológicos, socioculturais e econômicos, a formação dos hábitos saudáveis de vida ocorre à medida que a criança cresce, tendo os adultos como modelo e sofrendo grande influência da mídia e da escola em sua formação (FISBERG et al., 2000). Dessa forma, percebe-se, portanto, que a adequação de atitudes obtidas pelos escolares a favor da promoção da saúde está fortemente associada a valores que o professor e toda a comunidade escolar pode transmitir aos alunos no convívio escolar (SOBRAL; SANTOS, 2010).

A concretização de projetos de promoção da saúde no contexto escolar está apoiada no professor, o qual representa um elo importante e fundamental neste contexto (BUCHARLES; ALVERNE; CATRIB, 2013), pois, ao mesmo tempo em que trata do objeto, a alimentação do educando, o educador pode influenciar as percepções, hábitos e escolhas alimentares (FREIRE, 1997). 
A promoção de atividades educativas no ambiente escolar, na qual a alimentação tem sido colocada como uma ferramenta para a promoção da saúde constitui-se como estratégia de vital importância para o enfrentamento dos problemas de saúde do contexto atual (AZOLIN et al., 2010; SANTOS, 2005), sendo este um setor estratégico para a concretização de iniciativas de promoção da saúde (SCHMITZ et al., 2008). As políticas de saúde focadas na promoção de práticas alimentares saudáveis e estilo de vida ativo, para crianças e adolescentes, têm se tornado prioridade, especialmente, devido ao panorama da transição epidemiológica, nutricional e demográfica (JUZWIAK; CASTRO; BATISTA, 2013).

Nesse sentindo, pressupõe-se que o professor, através da educação em saúde, pode ser um forte aliado nesse processo, principalmente, por fazer parte do contexto da escola e da realidade da comunidade, por deter as ferramentas pedagógicas para a realização desse trabalho (MIRA, 2007) e por possuir estratégias educativas necessárias para a construção integrada do conhecimento (BUCHARLES; ALVERNE; CATRIB, 2013).

Diante do exposto, o objetivo do presente estudo foi verificar o conhecimento que professores do Ensino Fundamental, expostos ao Programa de Educação pelo Trabalho para a Saúde (PET/Saúde) "Promoção da saúde dos escolares", apresentaram acerca do papel da escola na formação dos hábitos alimentares dos escolares.

\section{Metodologia}

\section{Tipo do estudo}

Trata-se de um estudo do tipo longitudinal, quali-quantitativo, composto por professores do Ensino Fundamental I, do $1^{\circ}$ ao $5^{\circ}$ ano, de escolas públicas municipais da cidade de Amargosa-BA.

\section{Participantes}

Os participantes deste estudo estiveram imersos no Programa de Educação pelo Trabalho - PET/Saúde: "Promoção da saúde dos Escolares" por um período de três meses.

A participação no estudo foi voluntária, sendo os educadores esclarecidos quanto aos objetivos, métodos, sigilo e possibilidade de desistência de participação a qualquer momento.

\section{PET/Saúde: "Promoção da saúde dos Escolares”}

O PET/Saúde: "Promoção da saúde dos escolares" teve como objetivo contribuir para a formação integral de crianças e adolescentes, estudantes da rede pública de ensino do município de Amargosa-BA, por meio de ações de promoção, prevenção e atenção à saúde, com vistas ao enfrentamento das vulnerabilidades que comprometem o pleno crescimento e desenvolvimento de indivíduos nessa faixa etária. O programa foi desenvolvido em seis escolas municipais do Ensino Fundamental I, sendo cinco rurais e uma urbana, com o número de alunos variando entre 30 e 299, entre os meses de agosto de 2013 e novembro de 2014.

Durante os três meses de intervenção, em cada escola, foram desenvolvidas seis oficinas direcionadas aos escolares. Essas oficinas, embora tivessem o foco principal nos escolares, 
envolviam de forma ativa os professores, que participavam do desenvolvimento das mesmas, davam suas contribuições e, juntamente com os escolares, apreendiam novos conceitos sobre promoção da saúde, prevenção de doenças crônicas, prática de atividade física, alimentação saudável e promoção da qualidade de vida. Ao final de cada oficina, os planos de trabalho desenvolvidos pela equipe PET/Saúde eram disponibilizados aos professores. Tais planos continham, de forma detalhada, os objetivos geral e específico, os materiais e métodos e todo o referencial teórico utilizado na construção dos mesmos. Foram disponibilizadas, também, atividades extras, confeccionadas de acordo com as faixas etárias dos escolares, cujo objetivo era fornecer apoio aos professores para a continuidade do trabalho de promoção da saúde do escolar.

\section{Instrumento de coleta de dados}

Para a coleta de dados utilizou-se um questionário estruturado, contendo questões abertas e fechadas, desenvolvido pelo grupo do PET/Saúde e testado previamente, entre os integrantes do grupo, para assegurar o entendimento do formato das questões em relação aos objetivos traçados para o estudo, além de relatórios semanais construídos pelos "petianos" após as intervenções do programa.

Previamente ao início das atividades do PET/Saúde na escola, os professores responderam ao questionário estruturado contendo 17 questões, as questões fechadas apresentavam apenas uma resposta correta. Dentre as opções de respostas havia a "Não sei”. Os professores foram orientados a responder o questionário de forma individual, sem consultar qualquer outro material ou pessoa. Nesse estudo, avaliou-se qualitativamente o trabalho prévio dos professores com temas relacionados à nutrição e saúde e à visão dos mesmos enquanto peças fundamentais no processo de promoção da saúde dos escolares. Quantitativamente, foram avaliadas questões que versavam sobre hábitos alimentares, doenças crônicas não transmissíveis e o papel da escola na formação dos hábitos alimentares dos escolares.

Ao término das ações do programa PET/Saúde na escola, cerca de três meses, houve a reaplicação do questionário estruturado. Nesta etapa, os professores foram arguidos também sobre o trabalho desenvolvido pelo PET/Saúde e o que puderam vivenciar com a ação do mesmo.

Posteriormente, verificou-se o número de acertos e erros obtidos pelos professores em relação aos temas saúde e nutrição. Ao comparar o questionário antes e após a ação do programa, buscou-se verificar mudanças provocadas pelas intervenções sob os professores participantes, no que se refere a contribuições para o saber e para a prática docente individual.

\section{Análise dos dados}

Para a análise descritiva dos dados foram utilizados os softwares Microsoft Excel ${ }^{\circledR}$, versão 2010, e Bioestat ${ }^{\mathbb{R}}$ 5.0.

As variáveis foram analisadas descritivamente, segundo a frequência, medidas de tendência central e medidas de variabilidade.

A normalidade dos dados foi testada utilizando-se o teste estatístico D'Agostino onde se verificou a não normalidade dos mesmos $(\mathrm{p}<0,001)$.

Para testar a diferença entre os grupos, antes e após a intervenção, utilizou-se o teste de Wilcoxon para as variáveis ordinais. O nível de significância adotado foi de $5 \%$. 


\section{Resultados}

Participaram do estudo seis escolas municipais de Ensino Fundamental I, sendo cinco $(83,3 \%)$ da área rural e uma $(16,7 \%)$ da área urbana. Dos 24 professores que compunham o quadro docente dessas escolas, 14 (58,3\%) participaram do presente estudo. As perdas deveram -se à resposta de apenas um dos questionários $(33,4 \%, \mathrm{n}=8)$ e à participação em menos de $80 \%$ das atividades do Programa $(8,3 \%, \mathrm{n}=2)$.

A população estudada foi composta, em sua totalidade, por professores do sexo feminino. Em razão disso, optou-se por utilizar, doravante, a expressão “professoras" para marcar a homogeneidade do universo amostral em relação ao sexo.

Em relação à idade e ao tempo de atuação profissional, observou-se que a população era formada por mulheres jovens, com mediana de idade de 41 anos (22-57 anos) e com ingresso precoce no mercado de trabalho, visto que 50\% delas possuíam 20 anos ou mais de atuação profissional. Destas, $71,4 \%(\mathrm{n}=10)$ apresentavam vínculo empregatício efetivo.

No que se refere à escolaridade, a maioria das professoras $(92,9 \%, \mathrm{n}=13)$ cursou ou estava cursando o nível superior. Entre as que apresentavam formação de nível superior, $71,4 \%$ $(n=10)$ eram pedagogas, sendo que $57,1 \%(n=8)$ apresentavam pós-graduação. A formação profissional das participantes do estudo pode ser observada na Tabela 1.

Tabela 1. Formação profissional de professoras do ensino fundamental expostos a um programa de promoção da saúde dos escolares, Amargosa-BA, 2013-2014.

\begin{tabular}{clrc}
\hline \multirow{2}{*}{ Variáveis de formação profissional } & \multicolumn{2}{c}{ Frequência } \\
\cline { 3 - 4 } & & $\begin{array}{r}\text { Relativa } \\
\text { Ensino médio }\end{array}$ & $\begin{array}{c}\text { Absoluta } \\
\text { \% }\end{array}$ \\
\hline \multirow{4}{*}{ Graduação } & Regular & 1 & 7,14 \\
& Magistério & 11 & 78,57 \\
& Não respondeu & 2 & 14,29 \\
& Cursou & 11 & 78,57 \\
& Cursando & 2 & 14,29 \\
& Não cursou & 1 & 7,14 \\
Purso de graduação-graduação & Pedagogia & 10 & 71,43 \\
& Normal Superior & 2 & 14,29 \\
& Licenciatura em matemática & 1 & 7,14 \\
& Não cursou & 1 & 7,14 \\
& Cursou & 8 & 57,14 \\
& Cursando & 0 & 0,00 \\
Curso de pós graduação & Não cursou & 6 & 42,86 \\
& Psicopedagogia Institucional e Clínica & 2 & 14,29 \\
& Política de Planejamento Pedagógico & 4 & 28,57 \\
& Currículo didático e avaliação & 1 & 7,14 \\
& Aprendizagem de matemática & 1 & 7,14 \\
& Não cursou & 6 & 42,86 \\
\hline
\end{tabular}

Fonte: elaborado pelos autores a partir dos dados da pesquisa. 
O trabalho prévio com temas, como a alimentação saudável e a prática de atividade física na escola foi relatado por todas $(100 \%, \mathrm{n}=14)$ as participantes, no entanto, muitas relataram enfrentar dificuldades para trabalhar com tais temas no ambiente escolar. Os depoimentos mais observados foram aqueles relacionados com a falta de: conhecimentos específicos sobre alimentação saudável, espaço físico apropriado para a prática de atividade física e parceria com a família, especialmente em relação à alimentação dos escolares.

Das professoras questionadas, $92,9 \%(n=13)$ consideraram-se agentes fundamentais para a promoção da alimentação saudável e da prática de atividade física no ambiente escolar, como pode ser observado nos depoimentos:

Principalmente nas series iniciais, o professor é visto como modelo para os alunos e tudo o que é dito por ele é tomado como verdade. [Professora 2].

Os alunos acreditam e confiam no que os professores falam e fazem, por isso, acredito que somos agentes capazes de contribuir na formação da pessoa. [Professora 14]

Acerca dos erros e acertos obtidos pelas professoras, por meio do preenchimento dos questionários estruturados, antes e após as ações de promoção da saúde, na Tabela 2 é possível observar uma diferença estatística significativa na questão $17(\mathrm{p}=0,0425)$, que abordava a importância da escola na formação de hábitos alimentares dos escolares.

\section{Discussão}

Os resultados desse estudo reforçam que, nas séries iniciais da Educação Básica e em instituições voltadas à primeira infância, predominam educadores do sexo feminino. Fato também observado em um estudo publicado pela UNESCO (2004), no qual em uma população de quase cinco mil professores, de diferentes níveis de ensino, $81,3 \%$ destes pertenciam ao sexo feminino.

Este fenômeno da "feminização do magistério" mantém-se vivo nos dias atuais e está relacionado ao processo histórico de ampliação do número de instituições escolares, a partir do final do século XIX, e migração dos homens para atividades melhores remuneradas em outros setores da economia, impulsionados pela nascente indústria brasileira (CAVALCANTE; CORRÊA, 2012). De acordo com Silva (2011), o magistério é representado similarmente ao trabalho no lar, ao cuidar das crianças, sendo considerado uma continuidade da educação primária do lar e visto como uma profissão feminina. Segundo Freire (1993), a própria denominação "tia", dada pelos alunos às professoras, reforça a proximidade e identificação da professora com uma figura familiar e similar à materna.

O mesmo estudo desenvolvido pela UNESCO apresentou uma média de idade dos docentes de 37,8 anos, com concentração significativa desses profissionais nas faixas etárias de 26 a 35 anos e de 36 a 45 anos (33,6\% e 35,6\%, respectivamente). Comparado ao panorama internacional, os professores brasileiros, assim como os de países mais pobres, são relativamente mais jovens (UNESCO, 2004). 
Tabela 2. Respostas de professoras do ensino fundamental sobre nutrição e saúde, antes e após um programa de promoção da saúde dos escolares. Amargosa-BA. 2013-2014

\begin{tabular}{|c|c|c|c|c|c|c|c|c|c|c|}
\hline \multirow{3}{*}{ Questões } & \multicolumn{10}{|c|}{ Respostas antes da intervenção } \\
\hline & \multicolumn{2}{|c|}{$\begin{array}{l}\text { Todas } \\
\text { certas }\end{array}$} & \multicolumn{2}{|c|}{$\begin{array}{l}\text { Certas, mas } \\
\text { não todas }\end{array}$} & \multicolumn{2}{|c|}{$\begin{array}{l}\text { Certas e } \\
\text { erradas }\end{array}$} & \multicolumn{2}{|c|}{$\begin{array}{c}\text { Todas } \\
\text { erradas }\end{array}$} & \multicolumn{2}{|r|}{$\begin{array}{l}\text { Não } \\
\text { sabe }\end{array}$} \\
\hline & $\mathbf{n}$ & $\%$ & $\mathbf{n}$ & $\%$ & $\mathbf{n}$ & $\%$ & $\mathrm{n}$ & $\%$ & $\mathbf{n}$ & $\%$ \\
\hline $\begin{array}{l}\text { Q.4 - Sobre o tratamento não } \\
\text { medicamentoso do DM II }\end{array}$ & 9 & 64,29 & 2 & 14,29 & 0 & 0,00 & 0 & 0 & 3 & 21,43 \\
\hline Q.5 - Sobre o surgimento da HAS & 13 & 92,86 & 1 & 7,14 & 0 & 0,00 & 0 & 0 & 0 & 0,00 \\
\hline Q.7 - Sobre o surgimento das DCV & 6 & 42,86 & 0 & 0,00 & 7 & 50,00 & 0 & 0 & 1 & 7,14 \\
\hline Q.16 - Sobre os hábitos alimentares & 10 & 71,43 & 3 & 21,43 & 0 & 0,00 & 0 & 0 & 1 & 7,14 \\
\hline $\begin{array}{l}\text { Q.17 - Sobre o papel da escola na } \\
\text { formação de hábitos saudáveis }\end{array}$ & 6 & 42,86 & 7 & 50,00 & 0 & 0,00 & 0 & 0 & 1 & 7,14 \\
\hline
\end{tabular}

\begin{tabular}{|c|c|c|c|c|c|c|c|c|c|c|c|}
\hline \multirow{3}{*}{ Questões } & \multicolumn{10}{|c|}{ Respostas após intervenção } & \multirow{3}{*}{$\mathrm{p}$} \\
\hline & \multicolumn{2}{|c|}{$\begin{array}{l}\text { Todas } \\
\text { certas }\end{array}$} & \multicolumn{2}{|c|}{$\begin{array}{c}\text { Certas, } \\
\text { mas não } \\
\text { todas }\end{array}$} & \multicolumn{2}{|c|}{$\begin{array}{l}\text { Certas e } \\
\text { erradas }\end{array}$} & \multicolumn{2}{|c|}{$\begin{array}{c}\text { Todas } \\
\text { erradas }\end{array}$} & \multicolumn{2}{|c|}{$\begin{array}{l}\text { Não } \\
\text { sabe }\end{array}$} & \\
\hline & $\mathbf{n}$ & $\%$ & $\mathbf{n}$ & $\%$ & $\mathbf{n}$ & $\%$ & $\mathbf{n}$ & $\%$ & $\mathbf{n}$ & $\%$ & \\
\hline $\begin{array}{l}\text { Q.4 - Sobre o tratamento não } \\
\text { medicamentoso do DM II }\end{array}$ & 8 & 57,14 & 2 & 14,29 & 4 & 28,57 & 0 & 0,00 & 0 & 0,00 & 0.7874 \\
\hline Q.5 - Sobre o surgimento da HAS & 13 & 92,86 & 0 & 0,00 & 0 & 0,00 & 1 & 14,29 & 0 & 0,00 & 0.6547 \\
\hline Q.7 - Sobre o surgimento das DCV & 6 & 42,86 & 0 & 0,00 & 8 & 57,14 & 0 & 0,00 & 0 & 0,00 & 0.5751 \\
\hline Q.16 - Sobre os hábitos alimentares & 10 & 71,43 & 4 & 28,57 & 0 & 0,00 & 0 & 0,00 & 0 & 0,00 & 0.2807 \\
\hline $\begin{array}{l}\text { Q.17 - Sobre o papel da escola na } \\
\text { formação de hábitos saudáveis }\end{array}$ & 12 & 85,71 & 2 & 14,29 & 0 & 0,00 & 0 & 0,00 & 0 & 0,00 & $0.0425^{*}$ \\
\hline
\end{tabular}

p*: Variável sem distribuição normal (Teste de Wilcoxon)

DM II: Diabetes melito tipo 2; HAS: hipertensão arterial sistêmica; DCV: doenças cardiovasculares

Fonte: elaborado pelos autores a partir dos dados da pesquisa.

Observou-se que quase a totalidade das professoras participantes do estudo cursaram ou estavam cursando o nível superior. A Lei de Diretrizes e Bases da Educação Nacional (LDB), $\mathrm{n}^{\circ}$ 9.394/1996, de 20 de dezembro de 1996 determinou que:

A formação de docentes para atuar na educação básica far-se-á em nível superior, em curso de licenciatura, de graduação plena, em universidades e institutos superiores de educação, admitida, como formação mínima para o exercício do magistério na educação infantil e nos 5 (cinco) primeiros anos do ensino fundamental, a oferecida em nível médio na modalidade normal (BRASIL, 1996). 
Fato que pode justificar, no presente estudo, o número de professoras com formação superior. Esta deliberação, sobre a necessidade de formação específica em nível superior dos professores de educação infantil, pode ser vista como um avanço na direção da profissionalização da área (CERISARA, 2002). No entanto, o Brasil ainda não conseguiu superar o déficit na formação dos professores. A LDB determinou ainda que até o ano de 2007 todos os professores deveriam ser habilitados em nível superior ou formados por treinamento em serviço para atuarem na Educação Básica (BRASIL, 1996). Oito anos após esta determinação, observou-se no presente estudo professoras sem formação superior, lecionando no Ensino Fundamental I, o que pode estar relacionado aos cursos de formação superior estarem concentrados nas grandes cidades. Entretanto, com o advento dos cursos superiores de educação à distância estes estão contribuindo para a formação de professores em cidades do interior, como é o caso da cidade de Amargosa-BA (SAMPAIO et al., 2002).

O elevado nível de professoras pós-graduadas no presente estudo pode ter colaborado para uma elevada quantidade de acertos nas respostas dos questionários antes mesmo da intervenção educativa. Os resultados da aplicação do mesmo questionário em população de professores com menor graduação, comparado aos dados obtidos na população estudada, poderia revelar a influência que o fator escolaridade exerce sobre o conhecimento. Fernandez e Silva (2008) e Macedo, Cervato e Gambardella (2008) verificaram em seus estudos que 39,7\% e $21 \%$, respectivamente, dos professores entrevistados apresentavam pós-graduação completa ou em andamento.

Observou-se que a totalidade das professoras participantes do estudo trabalhava com o tema alimentação saudável e a prática de atividade física no ambiente escolar. No Brasil, a promoção da alimentação saudável no ambiente escolar tem sido foco de políticas públicas nas áreas de saúde e de educação, como: a Portaria Interministerial $\mathrm{N}^{\circ} 1.010$, de 08 de maio de 2006, que institui as diretrizes para a Promoção da Alimentação Saudável nas Escolas de educação infantil, fundamental e nível médio das redes públicas e privadas, que estimulam "ações de educação alimentar e nutricional, considerando os hábitos alimentares como expressão de manifestações culturais regionais e nacionais" ((BRASIL, 2006, p. 02); o Programa Nacional de Alimentação Escolar (PNAE), determinado através da Resolução CD/FNDE No 38, de 16 de julho de 2009 ((BRASIL, 2006, p. 03), que prevê a "educação alimentar e nutricional no processo de ensino e aprendizagem, que perpassa pelo currículo escolar, abordando o tema nutrição e saúde e o desenvolvimento de práticas saudáveis de vida, na perspectiva da segurança alimentar e nutricional"; e a Política Nacional de Alimentação e Nutrição (PNAN), aprovado pela Portaria $\mathrm{n}^{\mathrm{o}} 2.715$, de 17 de novembro de 2011, que incentiva o espaço escolar como ambiente para a educação alimentar e nutricional de crianças, a fim de contribuir para a formação de hábitos alimentares saudáveis (BRASIL, 2012). Algumas políticas preveem a inserção da nutrição e saúde no conteúdo programático, nos diferentes níveis de ensino, o que colabora para a formação de atitudes e valores que levam o escolar ao comportamento autônomo, revertendo em benefício à sua saúde e a daqueles que estão à sua volta (ASSIS et al., 2010).

Com relação às dificuldades enfrentadas pelas professoras para trabalhar a alimentação saudável e a prática de atividade física no ambiente escolar, observou-se que a falta de conhecimento específico na área foi um dos principais motivos citados por elas. Dessa forma, reconhece-se a necessidade da implantação de cursos de educação continuada, como forma de ampliar o conhecimento dos professores para que esses possam trabalhar, de forma mais segura, 
temas voltados à promoção da saúde dos escolares. O processo de educação continuada em saúde, como uma ferramenta de promoção da saúde, deve ser entendido como uma estratégia para habilitar profissionais para atuarem como agentes promotores de saúde. Esta ferramenta deve ser permanente, necessariamente ligada a uma ação dinâmica, ininterrupta e atualizada (LERVOLINO; PELICIONI, 2005).

Aliado ao conhecimento insuficiente sobre alimentação, nutrição e atividade física foi relatado pelas professoras que o espaço físico inapropriado para prática de atividade física e a falta de parceria com a família em relação à alimentação dos escolares compreendem as maiores barreiras vivenciadas no processo de educação em saúde. Ressalta-se que os problemas identificados pelos educadores, em sua maioria, foram problemas comuns a todas as escolas e as soluções devem surgir do coletivo, por meio de diagnóstico preciso, de objetivos a serem alcançados, da discussão, da tomada de decisão, da execução e da avaliação das etapas desenvolvidas.

A diferença de realidade entre as escolas rurais e a urbana foi notória, observando-se nas primeiras: dificuldade de acesso às escolas, espaço externo sem garantia de segurança para a realização das atividades e cobertura inapropriada, implicando em exposição prolongada dos escolares ao sol e a não realização de atividades em dias chuvosos, comprometendo de forma significativa o trabalho pedagógico da educação física. Em um estudo realizado por Soares-Neto et al. (2013), com base no Censo Escolar da Educação Básica 2011, constatou-se que apenas $0,6 \%$ das escolas brasileiras têm infraestrutura próxima da ideal para o ensino, incluindo quadra esportiva para a realização de atividade física. Evidencia-se a necessidade de políticas públicas mais amplas que visem diminuir as discrepâncias entre as escolas e promover condições mínimas de qualidade, para que a aprendizagem possa ocorrer em um ambiente escolar mais favorável.

A promoção de comportamentos alimentares saudáveis deve incidir com maior ênfase nos primeiros anos da infância para que os mesmos permaneçam ao longo da vida (ROSSI; MOREIRA; RAUEN, 2008). Dessa forma, a família exerce grande influência no processo de construção dos hábitos alimentares da criança e, consequentemente, do indivíduo adulto, pois desempenha um papel crucial no que diz respeito à compra e ao preparo dos alimentos, além do controle da qualidade dos mesmos. A falta de parceria da família dificulta o trabalho de educação alimentar e nutricional desenvolvido pela escola, já que as preferências alimentares das crianças são influenciadas pelas escolhas e pelos hábitos alimentares dos pais (ROSSI; MOREIRA; RAUEN, 2008).

A promoção da saúde é considerada uma estratégia importante no processo doençasaúde-cuidado e a educação alimentar e nutricional pode ser considerada um componente decisivo nesse processo (YOKOTA et al., 2010). A promoção da saúde é definida pela Carta de Ottawa (1986) como "o processo de capacitação da comunidade para atuar na melhoria da sua qualidade de vida e saúde, incluindo uma maior participação no controle deste processo". A educação alimentar e nutricional vem se mostrando uma importante ferramenta para a promoção de hábitos alimentares mais saudáveis, controle e prevenção de doenças crônicas não transmissíveis podendo, o conhecimento em nutrição, influenciar nas práticas alimentares e no estado nutricional de crianças e adultos (DEMINICE et al., 2007).

A grande maioria das participantes deste estudo considerou-se agente fundamental para a promoção da alimentação saudável e da qualidade de vida no ambiente escolar. O reconhecimento, por parte das professoras, como agentes promotoras de hábitos alimentares saudáveis e a postura consciente de sua atuação na formação dos hábitos alimentares das crianças são 
essenciais no processo de promoção da saúde dos escolares (BERNARDON et al., 2009; DAVANÇO; TADDEI; GAGLIANONE, 2004). Dessa forma, o sucesso das ações de promoção à saúde no ambiente escolar está diretamente relacionado a consciência crítica dos profissionais, como agentes fundamentais no processo de transformação do comportamento alimentar e da prática de atividade física de crianças e adolescentes (BERNARDON et al., 2009).

Davanço, Taddei e Gaglianone (2004), avaliaram os conhecimentos sobre nutrição de 51 professores expostos e não expostos a um programa de educação nutricional, em 08 escolas públicas no município de São Paulo e observaram que os professores expostos ao programa apresentaram-se melhor preparados conceitualmente e, também, mais sensibilizados quanto ao papel do professor e da escola enquanto transformadores da realidade, atribuindo a si a função de estimular hábitos alimentares saudáveis.

Quando aplicado, previamente, o questionário estruturado no presente estudo obteve-se um bom número de acertos pelas professoras, especialmente, referente às questões que abordavam temas sobre desenvolvimento saudável e infantil, hábitos alimentares e doenças crônicas não transmissíveis. Após a intervenção do programa PET/Saúde, verificou-se diferença no número de acertos, com aumento na questão referente ao papel da escola na formação de hábitos saudáveis.

O aumento na frequência de acertos sobre a importância da escola na formação de hábitos saudáveis dos escolares, pós-programa de promoção da saúde dos escolares, em conjunto com as observações verificadas nos relatórios construídos pelos "petianos" após as oficinas, nos permite dizer que não só as professoras, mas também a comunidade escolar (direção, coordenação, funcionários da alimentação, famílias), compreenderam a importância que o ambiente escolar possui no estímulo aos hábitos alimentares saudáveis e na prática de atividade física. Reconhecendo a escola como ambiente adequado para a prática da educação alimentar e nutricional, pois esta, normalmente, representa o primeiro grupo social depois da familia e, dessa forma, contribui para o desenvolvimento integral dos escolares.

A infância é considerada um momento decisivo para a construção e solidificação dos hábitos e atitudes (BUCHARLES; ALVERNE; CATRIB, 2013), pois os hábitos adquiridos na infância tendem a se solidificar na vida adulta e afetam o comportamento alimentar do indivíduo por toda a vida (DETREGIACHI, BRAGA, 2011; MAIA et al., 2012). Dessa forma, o desenvolvimento de programas de promoção da saúde no ambiente escolar, com foco em práticas alimentares saudáveis e atividade física se configura como ferramenta de amplo alcance e repercussão (GONÇALVES et al., 2008).

A implementação de programas de educação em saúde nas escolas e a criação de um ambiente favorável à saúde e à promoção de práticas alimentares e estilo de vida saudáveis constituem importantes estratégias para enfrentar problemas alimentares e nutricionais como obesidade e doenças crônicas não transmissíveis associadas (FERNANDES et al., 2009). A escola é um ambiente favorável para o desenvolvimento de ações educativas em saúde, através de um trabalho direcionado, sistematizado e constante (BUCHARLES; ALVERNE; CATRIB, 2013).

O reconhecimento da importância do trabalho desenvolvido pelo programa PET/ Saúde foi evidenciado em falas como: 
[...] o trabalho desenvolvido foi extremamente importante para a promoção de uma (re)educação nutricional e alimentar, tanto para os alunos quanto para mim enquanto professora, além de ter incentivado e estimulado a prática de atividades físicas... A equipe não se limitou a apresentar uma receita pronta de como se alimentar bem e saudável, mas desenvolveu uma série de açoes que nos levaram a refletir e a (re)pensar sobre nossos bábitos alimentares e, a partir da nossa reflexão, criar condições necessárias e suficientes para poder mudar nossas práticas. [Professora 14].

Ressaltando, dessa forma, que a promoção da saúde no ambiente escolar contribui não somente para mudanças de atitudes dos escolares em si, mas também de todo corpo docente escolar.

As escolas constituem-se em cenários favoráveis para a prática de atividades de educação em saúde, especialmente, por serem um ambiente onde os escolares passam maior parte do seu dia e por exercerem uma grande influência sobre os seus alunos nas etapas formativas e mais importantes de suas vidas (GONÇALVES et al., 2008). Nesse sentido, o professor é considerado o elemento principal no processo de educação nutricional dos alunos, por se encontrar em posição estratégica e em contato diário com os mesmos (DAVANÇO; TADDEI; GAGLIANONE, 2004).

Promover a adoção de hábitos alimentares saudáveis representa um grande desafio para profissionais da educação, pois o comportamento alimentar de crianças e adolescentes são influenciados pela mídia, pela família e pelos grupos sociais. No entanto, são nessas fases da vida que se constroem e se solidificam os hábitos e as atitudes em prol da qualidade de vida. Nesse sentido, verifica-se a importância da escola, como ambiente potencializador para o desenvolvimento de ações de educação em saúde, e do professor, como agente fundamental no processo de promoção da saúde, prevenção de doenças e do fortalecimento da autonomia dos escolares a favor da sua saúde a curto, médio e logo prazo, dentro e fora do ambiente escolar.

\section{Considerações finais}

Os participantes do presente estudo compreenderam professoras jovens, em sua grande maioria graduadas em pedagogia e com pós-graduação. Quando arguidas sobre os temas nutrição e saúde, houve diferença no número de acertos a tais questionamentos, antes e após a intervenção de um PET/Saúde desenvolvido com os escolares das instituições nas quais lecionavam.

Tais apontamentos demonstram que a promoção à saúde realizada com os escolares propiciou também às professoras a aquisição de conhecimentos importantes em relação à nutrição e à saúde, o reconhecimento da escola como ambiente adequado para formação de hábitos alimentares dos escolares, bem como o autorreconhecimento enquanto agentes fundamentais para a promoção da alimentação saudável e da qualidade de vida.

No entanto, outros estudos são necessários para avaliar o impacto de ações educativas que envolvem a escola e os professores na formação dos hábitos alimentares dos escolares. 


\section{Agradecimentos}

A toda equipe PET/Saúde pelo esforço na realização do programa. Aos escolares, seus familiares, professoras, merendeiras, enfim, a todos da comunidade escolar que acolheram o PET/Saúde e contribuíram para o sucesso do programa de promoção à saúde do escolar.

\section{Referências}

ANZOLIN, C. et al. Intervenções nutricionais em escolares. Revista Brasileira de Promoção a Saúde, Fortaleza, v. 23, n. 4, p. 297-306, out./dez., 2010. Disponível em: <http://www.unifor.br/images/pdfs/rbps/artigo01_2010.4.pdf>. Acesso em: 22 ago. 2013.

ASSIS, S. S. et al. Educação em saúde: proposta de utilização de um modelo no ensino de ciências. Revista Eletrônica do Mestrado Profissional em Ensino de Ciências da Saúde e do Ambiente, Niterói, v. 3, n. 2, p. 108-120, 2010. Disponível em:<http://www. ensinosaudeambiente.uff.br/index.php/ensinosaudeambiente/article/view/119/117>. Acesso em: 15 jan. 2015.

BERNARDON, R. et al. Construção de metodologia de capacitação em alimentação e nutrição para educadores. Revista de Nutrição, Campinas, v. 22, n. 3, p. 389-398, maio/jun. 2009. Disponível em: < http://www.scielo.br/pdf/rn/v22n3/v22n3a09.pdf>. Acesso em: 30 maio 2014.

BRASIL. Decreto n. 6.286, de 5 de dezembro de 2007. Institui o Programa Saúde na Escola - PSE, e dá outras providências. Diário Oficial [da] Republica Federativa do Brasil, Brasilia, 6 dez. 2007. Disponível em: <http://www2.camara.leg.br/legin/fed/decret/2007/ decreto-6286-5-dezembro-2007-565691-publicacaooriginal-89439-pe.html>. Acesso em: 17 fev. 2015.

Lei no 9.394/1996, de 20 de dezembro de 1996. Estabelece as diretrizes e bases da educação nacional. Diário Oficial da União, Brasília, 23 dez. 1996. Disponível em: <http://www.planalto.gov.br/ccivil_03/leis/19394.htm>. Acesso em: 30 mar. 2015.

BRASIL. Ministério da Educação. Resolução/CD/FNDE n 38, de 16 de julho de 2009. Dispõe sobre o atendimento da alimentação escolar aos alunos da educação básica no Programa Nacional de Alimentação Escolar - PNAE.

BRASIL. Portaria Interministerial $\mathbf{n}^{\mathbf{0}} \mathbf{1 . 0 1 0}$, de 8 de maio de 2006. Institui as diretrizes para a promoção da alimentação saudável nas escolas de educação infantil, fundamental e nível médio das redes públicas e privadas, em âmbito nacional. Brasília, 2006. Disponível em: <https://www.fnde.gov.br/fndelegis/action/UrlPublicasAction. php?acao=abrirAtoPublico\&sgl_tipo $=$ PIM\&num_ato $=00001010 \& s e q \_a t o=000 \& v 1$ _ ano=2006\&sgl_orgao=MEC/MS>. Acesso em: 09 abr. 2015

BRASIL. Ministério da Saúde. Política nacional de alimentação e nutrição. Brasília, 2012. Disponível em: <http://conselho.saude.gov.br/biblioteca/livros/politica_ alimentacao_nutricao.pdf> Acesso em: 30 mar. 2015 
BRASIL. Secretaria de Educação Fundamental. Parâmetros curriculares nacionais: introdução aos parâmetros curriculares nacionais. Brasília, 1997. Disponível em: <http:// portal.mec.gov.br/seb/arquivos/pdf/livro01.pdf>. Acesso em: 15 jan. 2015

BUCHARLES, D. G.; ALVERNE, M; CATRIB, A. M. F. Promoção da saúde e as escolas: como avançar. Revista Brasileira de Promoção a Saúde, Fortaleza, v. 26, n. 3, p. 307-308, jul./set., 2013. Disponível em: http://ojs.unifor.br/index.php/RBPS/article/view/2924/ pdf. Acesso em: 15 jan. 2015.

CARTA DE OTAWA. Primeira Conferência Internacional sobre Promoção da Saúde; novembro de 1986; Ottawa; Ca. Disponível em: <http://bvsms.saude.gov.br/bvs/ publicacoes/carta_ottawa.pdf $>$. Acesso em: 15 Jan. 2015

CAVALCANTE, L. I. C.; CORRÊEA L. S. Perfil e trajetória de educadores em instituição de acolhimento infantil. Cadernos de Pesquisa, São Paulo, v. 42, n. 146, p. 494-517, 2012. Disponível em: <http://www.scielo.br/pdf/cp/v42n146/10.pdf>. Acesso em: 31 maio 2015.

CERISARA, A. B. O referencial curricular nacional para a educação infantil no contexto das reformas. Educação \& Sociedade, Campinas, v. 23, n. 80, p. 326-345, set. 2002. Disponível em: <http://www.scielo.br/pdf/es/v23n80/12935>. Acesso em: 9 abr. 2015

DAVANÇO, G. M.; TADDEI, J. A. A. C; GAGLIANONE, C. P. Conhecimentos, atitudes e práticas de professores de ciclo básico, expostos e não expostos a curso de educação nutricional. Revista de Nutrição, Campinas, v. 17, n. 2, p.177-184, abr./jun., 2004. Disponível em: <http://www.scielo.br/pdf/rn/v17n2/21130.pdf>. Acesso em: 13 ago. 2013.

DEMINICE, R. et al. Impacto de um programa de educação alimentar sobre conhecimentos, práticas alimentares e estado nutricional de escolares. Alimentos e Nutrição, Araraquara, v.18, n. 1, p. 35-40, jan./mar. 2007. Disponível em: < http://serv-bib.fcfar.unesp.br/seer/ index.php/alimentos/article/view/130/141>. Acesso em: 13 ago. 2013.

DETREGIACHI, C. R. P.; BRAGA, T. M. S. Projeto “criança saudável, educação dez": resultados com e sem intervenção do nutricionista. Revista de Nutrição, Campinas, v. 24, n. 1, p. 51-59, jan./fev., 2011. Disponível em: <http://www.scielo.br/pdf/rn/v24n1/v24n1a05. pdf $>$. Acesso em: 23 jan. 2015.

ESCOBAR, A. M. U.; VALENTE, M. H. Sobrepeso: uma nova realidade no estado nutricional de escolares de Natal, RN. Revista Associação Medica Brasileira, São Paulo, v. 53, n. 5, p. 377-88, 2007. Disponível em: < http://www.scielo.br/pdf/ramb/v53n5/ a02v53n5.pdf > . Acesso em: 29 abr. 2015.

FERNANDES, P. S. et al. Avaliação do efeito da educação nutricional na prevalência de sobrepeso/obesidade e no consumo alimentar de escolares do ensino fundamental. Jornal de Pediatria, Rio de Janeiro, v. 85, n. 4, 2009. Disponível em: <http://www.scielo.br/pdf/ jped/v85n4/v85n4a08.pdf>. Acesso em: 30 maio 2014. 
FERNANDEZ, P. M.; SILVA, D. O. Descrição das noções conceituais sobre os grupos alimentares por professores de $1^{\mathrm{a}}$ a $4^{\mathrm{a}}$ série: a necessidade de atualização dos conceitos.

Ciência \& Educação, Bauru, v. 14, n. 3, p. 451-66, 2008. Disponível em: <http://www. scielo.br/pdf/ciedu/v14n3/a06v14n3.pdf >. Acesso em: 15 jan. 2015.

FISBERG, M. et al. Hábitos alimentares da adolescência. Pediatria Moderna, São Paulo, v. 36, n. 11, p. 724-734, 2000. Disponível em: <http://www.moreirajr.com.br/revistas. asp?fase $=$ r003\&id_materia=203>. Acesso em: 13 ago. 2013.

FREIRE, P. Pedagogia da autonomia: saberes necessários à prática educativa. 30. ed. São Paulo: Paz e Terra, 1997.

FREIRE, P. Professora sim, tia não: cartas a quem ousa ensinar. São Paulo: Olho D’água, 1993.

GONÇALVES, F. D. et al. A promoção da saúde na educação infantil. Interface, Botucatu, v. 12, n. 24, p. 181-92, 2008. Disponível em: <http://dx.doi.org/10.1590/S141432832008000100014>. Acesso em: 15 jan. 2015.

INSTITUTO BRASILEIRO DE GEOGRAFIA E ESTATÍSTICA. Pesquisa de orçamentos familiares 2008-2009: antropometria e sobrepeso e obesidade de crianças, adolescentes e adultos no Brasil. Rio de Janeiro: IBGE, 2010. Disponível em: <http://189.28.128.100/nutricao/docs/evento/reuniao_nacional/2010/dia30/pesquisa_ orcamento_familiar.pdf $>$. Acesso em: 4 abr. 2016.

JUZWIAK, C. R.; CASTRO, P. M.; BATISTA, S. H. S. S. A experiência da Oficina Permanente de Educação Alimentar e em Saúde (OPEAS): formação de profissionais para a promoção da alimentação saudável nas escolas. Ciência \& Saúde Coletiva, Rio de Janeiro, v. 18, n. 4, p. 1009-1018, 2013. Disponível em: <http://www.scielo.br/pdf/csc/v18n4/14. pdf>. Acesso em: 30 maio 2014.

LERVOLINO, S. A.; PELICIONI, M. C. F. Capacitação de professores para a promoção e educação em saúde na escola: relato de uma experiência. Revista Brasileira Crescimento e Desenvolvimento Humano, São Paulo, v. 15, n. 2, p. 99-110, 2005. Disponível em: <http:/ /www.revistas.usp.br/jhgd/article/viewFile/19762/21828>. Acesso em: 30 jun. 2014.

MACEDO, I. C.; CERVATO, A. M.; GAMBARDELLA, A. M. D. Estratégia de capacitação em educação nutricional para professores de educação infantil. Nutrição Brasil, Rio de Janeiro, v. 7, n. 1, jan./fev., 2008. Disponível em: < http://www.producao.usp.br/ bitstream/handle/BDPI/14143/art_MACEDO_Estrategia_de_capacitacao_em_educacao_ nutricional_para_professores_2008.pdf?sequence=1\&isAllowed=y $>$. Acesso em: 13 ago. 2013.

MAIA, E. R. et al. Validação de metodologias ativas de ensino-aprendizagem na promoção da saúde alimentar infantil. Revista de Nutrição, Campinas, v. 25, n. 1, p. 79-88, jan./fev., 2012. Disponível em: <http://www.scielo.br/pdf/rn/v25n1/a08v25n1.pdf >. Acesso em: 15 jan. 2015. 
MIRA, F. D. Capacitação de professores em alimentação saudável na rede municipal de Mutuípe, Bahia: alcances e limitações. 2007. 120 f. Dissertação (Mestrado em Alimento, Nutrição e Saúde) - Escola de Nutrição, Universidade Federal da Bahia, Salvador, 2007.

MOTTER, A. F. et al. Pontos de venda de alimentos e associação com sobrepeso/obesidade em escolares de Florianópolis, Santa Catarina, Brasil. Caderno de Saúde Pública, Rio de Janeiro, v. 31, n. 3, p. 620-632, mar, 2015. Disponível em: <http://www.scielosp.org/pdf/ csp/v31n3/0102-311X-csp-31-03-00620.pdf>. Acesso em: 5 abr. 2015.

ROSSI, A.; MOREIRA, E. D. M.; RAUEN, M. S. Determinantes do comportamento alimentar: uma revisão com enfoque na família. Revista de Nutrição, Campinas, v. 21, n. 6, p. 739-748, nov./dez., 2008. Disponível em: <http://www.educadores.diaadia.pr.gov.br/ arquivos/File/2010/artigos_teses/2010/Biologia/artigos/determinantes_alimento.pdf $\geq$. Acesso em: 29 abr. 2015.

SAMPAIO, C. E. M. et al. Estatísticas dos professores no Brasil. Revista Brasileira de Estudos Pedagógicos, Brasília, v. 83, n. 203/204/205, p. 85-120, 2002. Disponível em: <http://rbep.inep.gov.br/index.php/RBEP/article/viewFile/474/487>. Acesso em: 28 abr. 2015.

SANTOS, L. A. S. Educação alimentar e nutricional no contexto da promoção de práticas alimentares saudáveis. Revista de Nutrição, Campinas, v. 18, n. 5, p. 681-692, set./out., 2005. Disponível em: <http://www.scielo.br/pdf/rn/v18n5/a11v18n5.pdf>. Acesso em: 22 ago. 2013.

SCHMITZ, B. A. S. et al. A escola promovendo hábitos alimentares saudáveis: uma proposta metodológica de capacitação para educadores e donos de cantina escolar. Caderno de Saúde Pública, Rio de Janeiro, v. 24, n. 2, p. 312-322, 2008. Disponível em: < http://www. scielosp.org/pdf/csp/v24s2/16.pdf?origin=publication_detail>. Acesso em: 30 maio 2014.

SILVA, K. Currículo, gênero e identidade na formação de professores/as. 2011. 195 f. Dissertação (Mestrado em Educação) - Faculdade de Educação, Universidade Federal de Juiz de Fora, Juiz de Fora, 2011.

SOARES-NETO, J. J. et al. Uma escala para medir a infraestrutura escola. Estudos em Avaliação Educacional, São Paulo, v. 24, n. 54, p. 78-99, jan./abr., 2013. Disponível em: $<$ http://www.fcc.org.br/pesquisa/publicacoes/eae/arquivos/1786/1786.pdf>. Acesso em: 28 abr. 2015.

SOBRAL, T. N. A.; SANTOS, S. M. C. Proposta metodológica para avaliação de formação em alimentação saudável. Revista de Nutrição, Campinas, v. 23, n. 3, p. 399-415, maio/jun. 2010. Disponível em: <http://www.scielo.br/pdf/rn/v23n3/08.pdf>. Acesso em: 30 maio 2014.

UNESCO. O perfil dos professores brasileiros: o que fazem, o que pensam, o que almejam. São Paulo: Moderna, 2004.

WORLD HEALTH ORGANIZATION. Global strategy on diet, physical activity and health. Geneva: WHO, 2004. 
Rocha, A. S.; Facina, V. B.

YOKOTA, R. T. C. et al. Projeto "a escola promovendo hábitos alimentares saudáveis": comparação de duas estratégias de educação nutricional no distrito federal, Brasil. Revista de Nutrição, Campinas, v. 23, n. 1, p. 37-47, jan./ fev. 2010. Disponível em: <http://www. scielo.br/pdf/rn/v23n1/a05v23n1.pdf>. Acesso em: 30 maio 2014.

Artigo recebido em 26/08/2016. Aceito em 07/12/2016.

Endereço para contato: UFBA, Escola de Nutrição, Av. Araújo Pinho, n. 32, Canela, 40110-150, Salvador, BA, Brasil. 